ureters. The kidneys showed extensive interstitial fibrosis with tubular changes superimposed. In both these cases ureteric obstruction and subsequent bacterial invasion of the organs are sufficient to account for the microscopic lesions.

No case of typical chronic lead poisoning occurredconstipation, colic, peripheral neuritis, encephalopathy, were never seen-but one patient presented a blue lead line on the gums after 0.25 gram of lead given during a period of eleven weeks.

Autopsies were made on 17 of those who died, and the post-mortem findings were remarkably constant. In no case was any sign of regression observed in the growth. In some cases it showed advanced degeneration (but no central

Table showing the Results in 56 Cases of Malignant Disease treated by Colloidal Lead.

\begin{tabular}{|c|c|c|c|c|c|c|c|}
\hline \multicolumn{2}{|l|}{ Patient. } & Disease. & \multicolumn{2}{|c|}{$\begin{array}{l}\text { Duration of } \\
\text { Treatment. }\end{array}$} & \multicolumn{2}{|c|}{$\begin{array}{l}\text { Total } \\
\text { Dose. }\end{array}$} & Results. \\
\hline A. C. $\ldots$ & $\ldots$ & Ca. thyroidei & $169 \mathrm{~d}$ & days & $0.55 \mathrm{~g}$ & ram & Died. \\
\hline A. F. $\quad \ldots$ & $\ldots$ & Ca. thyroidei & 15 & , & 0.2 & " & Died. \\
\hline C.P. $\ldots$ & $\ldots$ & Ca. recti & 43 & , & 0.25 & $\because$ & Died. \\
\hline C. H. $\ldots$ & $\ldots$ & Ca. mammae & 225 & & 0.45 & $\because$ & I. S. Q. \\
\hline E. S. $\quad \ldots$ & $\ldots$ & Ca. mammae & 106 & $"$ & 0.3 & . & Worse. \\
\hline A. H. ... & $\ldots$ & Ca. mammae & 107 & $"$ & 0.35 & & Worse. \\
\hline L. A. $(a)$ & $\cdots$ & Ca. mammas & 107 & , & 0.05 & $"$ & Died. \\
\hline R. D. $\quad \ldots$ & $\ldots$ & Sarcoma femoris & 132 & $"$ & 0.57 & ", & Died. \\
\hline I. D. $\quad \ldots$ & $\ldots$ & Ca. ventriculi & 45 & $"$ & 0.17 & , & Died. \\
\hline A. B. $\quad \ldots$ & $\ldots$ & Ca. mammae & 63 & $"$ & 0.3 & $"$ & Worse. \\
\hline W. A. S. (b) & $\ldots$ & Ca. ventrieuli & 46 & $"$ & 0.22 & , & Died. \\
\hline S. H. $\quad \cdots$ & $\ldots$ & Ca. oesophagi & - & & 0.1 & " & Died. \\
\hline R.S. (c) & .. & Ca. soli oris & - & & 0.09 & , & I. S. Q. \\
\hline E. T. $\ldots$ & $\ldots$ & Ca. cervicis & - & & 0.1 & . & Died. \\
\hline S. G. $\ldots$ & $\ldots$ & Ca. cervicis & - & & 0.08 & , & Died. \\
\hline E. C. $(c)$ & $\ldots$ & Ca. cervicis & - & & 0.08 & r & I. S. Q. \\
\hline D. N. $\ldots$ & $\ldots$ & Epith. oris & - & & 0.08 & . & Died. \\
\hline S. W. (c) & $\ldots$ & Ca. ovarii & - & & 0.07 & " & I. S. Q. \\
\hline T. G. $\ldots$ & $\ldots$ & Melanomatosis & - & & 0.104 & , & Died. \\
\hline M. H. ... & $\ldots$ & Ca. mammae & 490 & days & 0.3 & , & I. S. $\mathbf{Q}$. \\
\hline W. K. ... & $\ldots$ & Epith. pharyngis & 115 & , & 0.508 & . & Died. \\
\hline T. R. ... & $\cdots$ & Ca. vesicae & 77 & $"$ & 0.254 & , & Died. \\
\hline H. $\dot{\mathbf{D}} . \quad \cdots$ & $\ldots$ & Ca. recti & 21 &, & 0.2 & " & Died. \\
\hline E.s. $\quad \ldots$ & $\ldots$ & Ca. mammae & 88 &, & 0.35 & , & Worse. \\
\hline C. S. R. & $\ldots$ & Ca. nodorum cervicis & 84 & " & 0.45 & " & Died. \\
\hline M. A. ... & $\ldots$ & Ca. vesicae & 42 & ", & 0.295 & , & Worse. \\
\hline A. B. P. $(d)$ & $\ldots$ & Ca. mammae & 105 & $"$ & 0.53 & , & Worse. \\
\hline A. W. H. & $\ldots$ & Epith. oris & 22 & $"$ & 0.2 & , & I. S. Q. \\
\hline C. J. $\quad \ldots$ & $\ldots$ & Epith. labii & 166 & $"$ & 0.6 & , & Worse. \\
\hline B. A. $\ldots$ & $\ldots$ & Epith. soli oris & 166 & 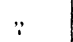 & 0.075 & " & Worse. \\
\hline M. B. $\ldots$ & $\ldots$ & Ca. cervicis & 54 & ", & 0.4 & , & I. S. Q. \\
\hline R. H. ... & $\ldots$ & Epith. soli oris & 36 & , & 0.3 & " & Died. \\
\hline A. B. B. $(c)$ & $\ldots$ & Ca. oesophagi . & 36 & , & 0.1 & , & I. S. $Q$. \\
\hline E. D. $\ldots$ & $\ldots$ & - Ca. ovarii & 65 & , & 0.35 & ,. & Died. \\
\hline C. C. $\quad \ldots$ & $\ldots$ & Epith. soli oris & 176 & ." & 0.575 & , & Died. \\
\hline K. P. $\quad \cdots$ & $\therefore$ & Ca. ovarii & 176 & , & 0.1 & $\because$ & Died. \\
\hline E. N: $\ldots$ & $\ldots$ & Ca. mammae & 207 & " & 0.26 & , & Died. \\
\hline M. R. ... & $\ldots$ & Ca. mammae & 28 & .. & 0.3 & " & Worse. \\
\hline w. C. ... & $\ldots$ & Epith. labii & 55 & , & 0.3 & .. & Died. \\
\hline A. G. B. & $\ldots$ & Ca. oesophagi & 43 & , & 0.3 & , & Died. \\
\hline M. C. ... & $\ldots$ & Ca. ovarii & 35 & $"$ & 0.25 & ,. & Died. \\
\hline W. G. (c) & $\ldots$ & Ca soli oris & 35 & " & 0.1 & .. & I. S. Q. \\
\hline F. B. ... & $\ldots$ & Ca. oesophagi & 35 & , & 0.1 & $"$ & Died. \\
\hline W. P. ... & $\ldots$ & Ca. recti & 35 & " & 0.1 & .. & Died. \\
\hline M. N. ... & $\cdots$ & Ca. vesicae & 41 & , & 0.29 & , & Worse. \\
\hline E. M. ... & $\ldots$ & Ca. vesicae & 41 & " & 0.29 & $"$ & Worse. \\
\hline D. N. (c) & $\ldots$ & Ca. mammae & 98 & $"$ & 0.4 & ." & Worse: \\
\hline G. s. (e) & $\ldots$ & Epith. tonsillae & 20 & $\therefore$ & 0.2 & . & Died. \\
\hline F. $0 . \ldots$ & $\ldots$ & Ca. cervicis & 74 & $"$ & 0.5 & $\because$ & Died. \\
\hline A. G. ... & $\ldots$ & Epith. soli oris & 86 & $"$ & 0.6 & " & Died. \\
\hline T. C: $\quad \ldots$ & $\ldots$ & Epith. oris & 147 & " & 0.5 & . & Died. \\
\hline A. L. $\ldots$ & $\ldots$ & Ca. vesicae & 58 & , & 0.4 & $"$ & Died. \\
\hline A. N. B. (c) & $\ldots$ & Ca. mammae & 94 & " & 0.45 & $"$ & Improved. \\
\hline R. M. ... & $\ldots$ & Ca. mammae & 36 & $n$ & 0.2 & $"$ & Died. \\
\hline F. T. $\ldots$ & $\ldots$ & Ca. mammae & 197 & ", & 0.6 & .• & I. S. Q. \\
\hline 7. S. B. (c) & .. & Ca prostatae & 21 & $"$ & 0.32 & ., & I. 8. Q. \\
\hline
\end{tabular}

(a) This patient also had diabetes. (b) Died of haematemesis. (c) Iieft hospital at own request. (d) Still under treatment. (c) Refused further treatment. necrosis, and no change which is not commonly seen when no lead at all has been given), in others there was no degeneration whatever, and in every case the mass of growth was larger than when treatment commenced. In nearly every instance the brain, liver, and kidneys showed evidence of damage as follows. In the brain there was extreme superficial (subarachnoid) oedema, with free fluid at the base. The chroroid plexuses were markedly oedematous. The liver showed extreme fatty degeneration. Apart from the cases of uraemia, the kidneys showed no macroscopic change. In most the cells of the convoluted tubules stained badly and showed some degree of desquamation, but it is possible that this is largely, if not entirely, a past-mortem process. But the localization of the changes is noteworthy : in no case was any abnormality discovered in the glomeruli or the cells of the loop of Henle or the collecting and straight tubules. In view of the fact that these appearances are not such as are met with in cases of malignant disease treated by other methods it is fair to presume that they directly result from the toxic action of the lead preparation employed.

\section{Final Results.}

Of the 56 patients treated one only-with a small supraclavicular gland which appeared one year after amputation of the breast for carcinoma-showed definite improvement, the gland being now only just palpable, whereas before it was about the size of an almond, and quite visible. Although clinically a definite diagnosis of secondary malignant disease was made, there is no proof that the gland was in fact malignant.

No appreciable change took place in 12 , but of these 7 received admittedly inadequate treatment-2 because they were so ill that it was decided to leave them in peace, 5 becanse they refused further injections. Five received from 0.3 to $0.6 \mathrm{gram}$ of lead in all, but the local condition remained unchanged. Another 11 were actually worse after treatment, of whom 2 received less than 0.3 gram of lead in all (one was considered too ill to receive more, the other refused). Nine received from 0.3 to $0.6 \mathrm{gram}$, in spite of which the malignant growth progressed. Thirty-two died, of whom 8 had received only one injection each. In other words, of 40 patients who received sufficient lead to warrant the expectation of some benefit, if any ever occurs, 22 died, 11 were clearly worse, 6 showed no change in either direction, and only one in any way improved. (Full results, with total dosage, are given in the accompanying table.)

Of 40 patients who have received 0.2 gram or more of colloidal lead intravenously, only one has shown any improvement,. while the majority are dead or obviously much worse than before treatment. So far, then, as my observations go there is no support for the statement that colloidal lead exerts a beneficial influence upon the progress of a makignant growth. Moreover, it is certainly a difficult and dangerous therapeutic method.

\section{SYPHILIS OF THE HEART. \\ BY \\ I. HARRIS, M.D.,} HONORARY PHYSICIAN, LIVERPOOL HEART HOSPITAL.

Ir is of the utmost importance to recognize syphilis of the heart, this being one of the few heart affections which almost invariably yield to treatment. In many cases, it is true, the improvement due to antispecific treatment is not pronounced; but there are doubtless numerous cases of cardiac syphilis in which proper treatment has effected a complete cure. To overlook a case of syphilis may mean the whole difference between normal health and permanent disability, and sometimes even between life and death.

The incidence of syphilis in heart disease has been greatly underestimated in the past, and there are but scant references to it in the older textbooks. Mackenzie, for instance, dismisses it with a few words, and authors like Romberg ${ }^{2}$ actually express the opinion that syphilis of the heart is rare. As a matter of fact syphilis is a 
very common cardiac affection, but unfortunately in the majority of cases it is not recognized.

This paper is based on a hundred cases of syphilis of the heart taken from patients attending the Heart Hospital; they represent about 9 per cent. of all cases at this institution.

It is obvious that patients with straightforward syphilis do not attend heart hospitals. The incidence of cardiac syphilis in patients attending venereal disease clinics must be considerable, and no doubt a good percentage of neurosyphilitics have damaged hearts. Syphilis of the heart must therefore be a common affection. In the great majority of the cases the true character of the disease was recognized in the first instance at the Heart Hospital, although many of these people were attending other institutions and some had been seen by prominent consultant physicians. Obviously the diagnosis of syphilis of the heart is very difficult.

At the outset it is well to recognize that there is not one single method, taken by itself, on which we may rely absolutely for the diagnosis of cardiac syphilis. In order to make a reasonably certain diagnosis of cardiac syphilis it is essential to employ all procedures available for the investigation of the disease; a single method cannot absolutely be relied on, but employed in conjunction with other methods, the evidence of cardiac syphilis may be so strong as to amount to a certainty.

The methods used are the Wassermann test, examination of the physical signs, electro-cardiographic investigation, study of the symptoms and history, and the use of antispecific treatment.

\section{The Wassermann Test.}

We depend a great deal on this test, but it is not absolutely reliable; two specimens from the same patient sent to different laboratories will. sometimes give contradictory results, owing in some instances to inaccuracy, and in others to difference in the methods employed. Moreorer, eren in this country, as is well known, a positive Wassermann reaction does not invariably denote syphilis; it is beliered that tuberculosis and infective endocarditis may, in the absence of syphilis, give rise to a positive reaction; it must also be borne in mind that a positive reaction may indicate only congenital syphilis. We actually have an instance of a positive Wassermann reaction in a grandchild and a grandmother, and numerous cases of nembers of a family with such reactions which can only be explained by the hereditary factor. On the other hand, a negative result does not mean that the patient is free from syphilis. There seems to be a general consensus of opinion that in the second stage of syphilis a positive reaction is the rule.

In heart cases, however, we are dealing mainly with latent chronic syphilis, and there are without doubt a relatively large number of cases of cardiac lues which give a negatire Wassermann reaction. For instance, in one almost certain case of cardiac syphilis repeated Wassermann tests of the blood serum were negative, and the spinal fluid alone gave a positive reaction. Still the fact remains that a positive reaction in this country connotes syphilis in more than 90 per cent. of all cases.

I have profolend faith in a positive Wassermann reaction for two reasons. In a large number of positive cases there was found corroborative evidence of lues in the form of neuro-syphilis. More significant still, many of these cases responded to antisyphilitic treatment to such an extent as to leave no doubt about the character of the disease.

I think wo are justified in concluding that a positive reaction, cven with a single plus, goes a long way towards the establishment of a diagnosis of cardiac syphilis: still it does not indicate that a particular heart affection is syphilitic.

Clinical Eridence of Cardinc Syphilis.

Clinical evidence which is absolutely pathognomonic for syphilis of the heart does not exist. We diagnose heart disease by abnormal functions which it causes, but these manifest themselves in the same way, whether structural alteration has been caused by syphilis or not. Disease of the auriculo-ventricular bundle may give rise to block, whether the disease is due to syphilis or to other factors. I maintain, however, that in many instances it is possible to diagnose syphilis of the heart with a high degree of probability from the clinical evidence alone, and in the majority of cases this evidence is such as to raise a strong suspicion of syphilis.

Broadly speaking, there are two features which are characteristic for cardiac syphilis. As is well known, this infection attacks the aorta and the coronary arteries, and disease of the latter gives rise to various affections of the myocardium. Syphilis affects the heart muscle with much greater frequency than does any other agent known to cause heart disease; there may be syphilitic aortitis, or aortic regurgitation, or other forms of infection, but usually the myocardium will also be damaged.

We may contrast this with the rheumatic valvular heart, where the inyocardium is relatively seldom affected. Out of 88 electro-cardiograms of cases of cardiac syphilis, only 9 were normal; in the same number of cardiograms taken from rheumatic ralvular heart cases 42 were normal. The cases of rheumatic origin were very much more advanced clinically than the syphilitic cases, so that the incidence of myocarditis in the rheumatic heart in relation to the syphilitic is relatively much less than these figures show.

This point is of practical importance in the diagnosis of syphilis. Take a case of aortic regurgitation in which, although it is not a very advanced case, there is evidence of myocarditis; this circumstance in itself favours the diagnosis of cardiac syphilis. In syphilis, moreover, the physical signs of a particular cardiac affection are not generally clean cut, the clinical picture is not usually true to type. In a case of rheumatic aortic regurgitation, for instance, the clinical signs are usually definite and correlated. There may be pronounced enlargement of the left rentricle, and the apex beat will be pointing outwards and downwards. There are usually such indications also as a pronounced water-hammer pulse, the different signs being correlated in a certain proportion. We may find such a picture occasionally in syphilitic aortic regurgitation, but in the majority of cases the clinical picture will be atypical. For instance, from an examination of the aortic area we may expect a large left ventricle and the typical appearance of the patient, but absence of one or the other indication is frequently observed. Again, in many instances, on examination of the heart we have difficulty in placing the abnornal signs in a definite category. The heart does not seem to be normal, and yet there are no distinct signs of valvular trouble; there is no enlargement in a given direction. We may be tempted to label it "tired" or "irritable" heart; it does not really fit in properly with either. In such circumstances it is advisable to investigate the case from the point of view of syphilis.

Passing from the general to the particular, aortitis is probably a most common event in syphilis; it must be remembered that syphilitic aortitis usually means syphilitic myocarditis. We may expect increased dullness over the aortic area, but this is not always easy to make out. In the early stage of aortitis we often depend for the diagnosis entirely on accentuation or alteration of the second aortic sound. I want particularly to emphasize the point that accentuation of the second aortic sound in the absence of high hlood pressure, in cases where there is either a history of syphilis or a positive Wassermann reaction, is quite sufficient evidence for the diagnosis of syphilitic aortitis, and, incidentally, syphilitic myocarditis. Usually the left ventricle is slightly enlarged; often there is a systolic aortic murmur, a diastolic murmur appearing later. Characteristic of these murmurs is also the fact that they cannot be relied on to be always audible-they appear and disappear. It is easier to distinguish between aortic regurgitation due to syphilis and aortic regurgitation due to rheumatic ferer, than between the former and aortic trouble secondary to such conditions as high blood pressure.

Syphilis does not seem to be a common factor in mitral disease. I have, however, had a number of typical cases of mitral stenosis with a positive Wassermann reaction and no history of rheumatic fever. Is mitral stenosis sometimes due to congenital syphilis? Syphilitic myocarditis, cardiac irregularities, extra-systole, auricular 
fibrillation, heart-block, and branch bundle lesion aro all common in syphilis, while the "large silent heart" is sometimes caused by it, and I have known instances of syphilitic pericarditis. Infective endocarditis sometimes gives a positive Wassermann reaction, and it is assumed in this case that such a reaction does not mean syphilis. It is, however, interesting that Byrom Bramwell, ${ }^{3}$ in a book published before the Wassermann test camo into vogue, gives syphilis as one of the causes of infective endocarditis; so acute an observer must have had good reason for his belief.

\section{Symptoms.}

Broadly speaking, symptoms of heart failure aro tho same, whether the underlying cause is syphilis or something else. It has been asserted that nocturnal dyspnoea is characteristic of cardiac syphilis. This has not been my experience, but as many of my cases are early cases of syphilis it is possible that if we take only advanced cases nocturnal dyspnoea may be more frequent. The one characteristic symptom of syphilis in my cases was cardiac pain, which was present in 70 per cent., but this pain has not usually the characteristic features of a classical angina pectoris. In my experience the great majority of typical cases of angina are not due to syphilis. The pain in the syphilitic variety is not so intense, does not appear so suddenly, and differs often in distribution from the pain met with in true angina; occasionally, however, the pain is similar.

The next important symptom is the gastric pain; pain is frequently referred to the stomach, simulating gastric ulcer, but tho gastric symptoms are easily distinguishable from those which may be due to heart failure.

\section{Electro-cardiographic Evidence.}

The electro-cardiogram gives information about the condition of the myocardium and also the nature of different irregularities. The great majority of electro-cardiographic abnormalities, however, are not characteristic of syphilis, and only denote a damaged heart muscle. They are, however, of the utmost importance in the diagnosis of cardiac syphilis, because in many instances it is by means of the electro-cardiograph that we are able to demonstrate conclusively that there is something wrong with the heart. In my experience, however, there is one type of electrocardiogram characteristic of syphilis-at least, I havo so far not seen it in any other disease. It consists of certain wavelets all over tho electric lino.

Blood pressure reading yields nothing characteristic of syphilis of the heart; the majority of cases do not show abnormal blood pressure reading.

The result of treatment is often a valuable aid in diagnosis. A patient was admitted into hospital suffering from gastric symptoms, but obviously very ill. The electrocardiograph revealed branch bundle lesion, a condition invariably fatal if not due to syphilis. In this case syphilis was subsequently admitted by the patient. Antispecific treatment of a few weeks' duration was sufficient to restore the patient to practically normal health, and the electrocardiogram became normal. Another patient developed a heart affection which was diagnosed as tired heart; he got worse, was able.to walk only a yard or two, and became almost blind. He denied syphilis. After admission to the Heart Hospital the Wassermann reaction was found to be double plus, and antisyphilitic treatment was so effective that this man is now ablo to follow his employment. In this case, no doubt, the diagnosis of syphilitic myocarditis was correct. All cases of cardiac syphilis do not show such good results under treatment, but in my experience the great majority improve definitely.

I have said sufficient to make it clear that from clinical evidence alone it is quite impossible in every case to diagnose syphilis of the heart with absolute certainty. Tho disease is very common. Those who concentrate on the subject will probably make fewer errors in diagnosis than others, but all sometimes overlook a case of cardiac syphilis. It is obviously a very serious matter to leave a case of syphilis without treatment. In my opinion we have no alternative but to adopt the Wassermann test is a routine procedure for all cases suffering from heart disease. A positive reaction, particularly in a patient with some cardiac trouble, ought to be sufficient indication for a prolonged course of antisyphilitic treatment. We are making this test part of the routine examination at the Heart Hospital.

I am indebted to $\mathrm{my}$ house-physicians, $\mathrm{Dr}$. Wilson and $\mathrm{Dr}$. Waters, for their valuable help in connexion with the case-taking.

REFERENCES.

${ }^{1}$ Mackenzie: Text Book of Heart Disease. ${ }^{2}$ Romberg: Krankheiten des Herzens. 3 Byrom Bramwell: Text Book of Heart Diseass

\section{SOME FUNDAMENTAL FACTORS IN THE TREAT- MENT OF PULMONARY TUBERCULOSIS.}

BY

SAMUEL H. STEWART, M.D.EDIN. SOUTHPORT;

LATE MEDICAL SUPERINTENDENT, BELFAST MUNICIPAL SANATORIUM.

Is tho search for guiding principles in dealing with cases of pulmonary tuberculosis it is more instructive to approach the subject from the point of view of objective in treatment than to attempt a classification of methods.

Tho discovery of tho tuberclo bacillus by Koch led to the rational adoption of all those measures calculated to stimulate the normal resources of the body so that the patient might overcome the infecting micro-organismindirect therapy. It was also to be expected that direct therapy, in the form of vaccines and serums, would emerge from the discovery. The aim of the direct and indirect therapies is, therefore, similar, for the objective in both instances is to overcome the tubercle bacillus on the lines of immunization, producing a serological immunity.

The issue is thus simplified, for, whether the patient is aided by such traditional methods as good food and fresh air in overcoming the infection, or whether vaccines and serums are administered, it is assumed that the toxinantitoxin balance is involved, and that increase of the antitoxic content will lead to healing. The terms "toxin" and "antitoxin" are used here in the widest sense.

Now the existence of a toxin-probably entirely endotoxin-is established, but what evidence is available in favour of the existence of a specific antitoxin in tho serological sense? That the human body must have some method of dealing with tubercle toxin is beyond question. Sanatorium principles and probably tuberculin therapy heighten the capacity to withstand tuberculous toxaemia, but the vital point remains: Does a highly positive resistance to toxaemia on the part of the patient necessarily overcomo the tuberculous infection or lead to healing of the diseased focus? In other words, is the defence against the disease purely a local histological problem independent of systemic resistance beyond that required to maintain life?

In dealing with tuberculosis we have becomo so accustomed to accepting direct and indirect therapy as resting on an established basis that it may seem absurd even to open the question. Still, the answer to the previous query involves the validity of the present attitude to the treatment of this disease.

My survey covers some clinical and experimental aspects of tuberculin therapy, clinical observations, and pathological findings. I wish to emphasize that this survey is only an expression of my attitude to the question raised.

The presence of an antitoxin in the bluod has not been proved by direct tests; besides, if such an antitoxin exists, its presence should be manifest in clinical experience.

\section{TUberculin.}

To obtain evidence of this antitoxin as contrasted with detoxication tuberculin was studied. The first point to become prominent was that relatively enormous doses could be administered at the end of a gradually increasing course without any apparent improvement in the pulmonary lesion. In such a case the patient has obviously increased detoxicating power, the general condition may also be good, and yet such a favourable situation is not coincident with healing power. 